OAJIS

Journal of

Information

Systems

is.its.ac.id/pubs/oajis/

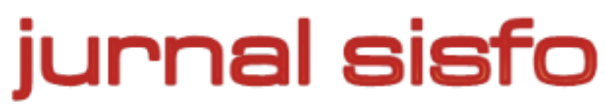

Jurnal Sisfo Vol. 07 No. 01 (2017) 47-58

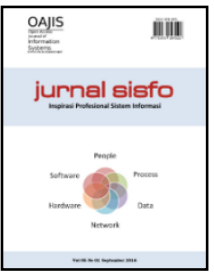

\title{
Penerapan Metode Multi Factor Evaluation Process untuk Pemilihan Tanaman Pangan di Kabupaten Musi Rawas
}

\author{
Yogi Primadasa*, Veradilla Amalia
}

Program Studi Sistem Informasi, STMIK Bina Nusantara Jaya Lubuklinggau

\begin{abstract}
Musi Rawas Regency is a potential land with its biodiversity as the main factor in the development of food crop sector. The diversity of the land includes irrigation, lebak, rainfed and dry land. Well-planned and well-developed sustainable food crop programs have a positive impact on joint policy and commitment in appointing Musi Rawas Regency as a "food barn". Therefore, a system is needed to facilitate the government of Musi Rawas Regency to determine what kind of food crops are suitable to be cultivated each region. This research aims to develop a Decision Support System as an alternative in the selection of existing food crops in Musi Rawas Regency by using Multi Factor Evaluation Process Method. This method gives subjective consideration of factors that are considered important. In this research, several factors were taking into consideration, such as the characteristics of land, environment, rain-fed and nursery. The result of this research is a ranking that will be used as a reference by the decision makers in selecting the suitable food crops.
\end{abstract}

Keywords: Decision Support System, Crops, Multi Factor Evaluation Process Method

\begin{abstract}
Abstrak
Kabupaten Musi Rawas memiliki potensi lahan yang luas dengan keanekaragaman hayati yang merupakan modal utama dalam pengembangan sektor tanaman pangan. Keanekaragaman lahan tersebut meliputi lahan irigasi, lebak, tadah hujan dan lahan kering. Program tanaman pangan yang terencana dengan baik dan berkelanjutan berdampak positif terhadap kebijakan dan komitmen bersama dalam mengangkat Kabupaten Musi Rawas sebagai "lumbung pangan". Oleh karena itu, dibutuhkan sistem untuk memudahkan pemerintah Kabupaten Musi Rawas dalam menentukan pilihan tanaman pangan yang cocok untuk dibudidayakan di setiap daerah. Dalam penelitian ini dikembangkan Sistem Pendukung Keputusan sebagai alternatif dalam pemilihan tanaman pangan yang ada di Kabupaten Musi Rawas dengan menggunakan metode Multi Factor Evaluation Process. Metode ini memberikan pertimbangan yang subyektif terhadap faktor yang dianggap penting. Dalam penelitian ini, faktor yang menjadi pertimbangan adalah karakteristik lahan, lingkungan, tadah hujan dan pembibitan. Hasil dari penelitian ini berupa perangkingan yang nantinya akan menjadi tolak ukur dalam pengambilan keputusan terkait pemilihan tanaman pangan yang cocok di Kabupaten Musi Rawas.
\end{abstract}

Kata kunci: Sistem Pendukung Keputusan, Tanaman Pangan, Metode Multi Factor Evaluation Proses

(C) 2017 Jurnal SISFO.

Histori Artikel : Disubmit 13 Agustus 2017; Diterima 27 September 2017; Tersedia Online 4 Oktober 2017

*Corresponding Author

Email address: yogiak45@gmail.com (Yogi Primadasa) 


\section{Pendahuluan}

Kabupaten Musi Rawas dengan potensi lahan yang luas dengan keanekaragaman hayati yang merupakan modal utama dalam pengembangan sektor tanaman pangan dan hortikultura. Keanekaragaman lahan tersebut meliputi lahan irigasi, lebak, tadah hujan dan lahan kering. Kebijakan pembangunan tanaman pangan dan hortikultura di Kabupaten Musi Rawas multak dilakukan melalui program-program yang tepat, jelas dan terarah sesuai dengan potensi yang ada, sehingga pada akhirnya dapat meningkatkan pendapatan dan kesejahteraan petani. Program tanaman pangan dan holtikultura yang terencana dan terpogram secara baik dan berkelanjutan berdampak positif terhadap kebijakan dan komitmen bersama dan mengangkat Sumatra Selatan pada umumnya dan Musi Rawas khususnya sebagai "lumbung pangan" [1].

Sehubungan dengan hal ini, pemerintah Kabupaten Musi Rawas sigap untuk memajukan kesejahteraan petani dengan program tanaman pangan yang tepat sesuai dengan keadaan lahan yang ada. Oleh sebab itu, pemerintah Kabupaten Musi Rawas khususnya Dinas Ketahanan Pangan Kabupaten Musi Rawas mendapatkan tugas khusus untuk memilih tanaman pangan yang tepat dalam pengembangan tanaman pangan yang ada di Kabupaten Musi Rawas.

Sistem Pendukung Keputusan merupakan sistem informasi yang interaktif untuk membantu pengambilan keputusan dalam situasi semitersktruktur dan situasi yang tidak terstruktur seperti ini [2]. Dengan adanya sistem pendukung keputusan dapat membantu kepala dinas selaku pengambil keputusan untuk memilih tanaman pangan yang layak ditanam oleh petani-petani di Kabupaten Musi Rawas. Sistem pendukung keputusan yang saat ini berkembang ada bermacam-macam [3], salah satunya metode Multi Factor Evaluation Process. Pengambilan keputusan menggunakan metode Multi Factor Evaluation Process dilakukan secara subyektif dan intuitif dengan menimbang beberapa faktor yang berpengaruh terhadap alternatif [4]. Oleh sebab itu Sistem Pendukung Keputusan menggunakan Metode Multi Factor Evaluation Process menjadi alternatif bagi pengambil keputusan dalam menentukan pilihan tanaman pangan yang akan ditanam.

\section{Tinjauan Pustaka/Penelitian Sebelumnya}

\subsection{Sistem Pendukung Keputusan}

Sistem Pendukung Keputusan merupakan sistem informasi yang interaktif untuk membantu pengambilan keputusan dalam situasi semitersktruktur dan situasi yang tidak terstruktur [2,10]. Sistem Pendukung Keputusan merupakan penerapan suatu sistem informasi yang bertujuan untuk membantu pimpinan selaku pengambil keputusan [4].

\subsection{Metode Multi Factor Evalaution Process (MFEP)}

Pengambilan keputusan menggunakan metode Multi Factor Evaluation Process dilakukan secara subyektif dengan menimbang beberapa faktor yang berpengaruh terhadap alternatif [5].

Langkah-langkah proses perhitungan menggunakan metode MFEP, yaitu $[6,7,8]$ :

1) Menentukan faktor dan bobot faktor dimana total pembobotan harus sama dengan $1\left(\sum\right.$ pembobotan $=$ 1) atau disebut factor weight.

2) Mengisikan nilai tiap faktor yang di perlukan dalam proses pengambilan keputusan, nilai yang dimasukan merupakan nilai objektif yaitu factor evaluation yang nilainya $0-1$

3) Proses perhitungan weight evaluation merupakan perhitungan antara factor weight dan factor evaluation dengan penjumlahan, dari hasil weight evaluation dapat menentukan hasil evaluasi. 
Dari langkah proses perhitungan menggunakan metode MFEP di atas dapat direalisasikan sebagai berikut:

1) Perhitungan nilai bobot evaluasi faktor ditunjukkan dalam persamaan (1).

$$
E F=\frac{\Sigma x}{\Sigma x \max }
$$

Keterangan:

$$
\begin{array}{ll}
\boldsymbol{E F} & \text { : Evaluasi Faktor } \\
\mathbf{X} & \text { : Nilai subkriteria } \\
\mathbf{X} \text { max } & \text { : Nilai x max }
\end{array}
$$

2) Perhitungan nilai bobot evaluasi ditunjukkan dalam persamaan (2).

$$
W E=F W x E
$$

Keterangan :

$\boldsymbol{W E}:$ Nilai bobot evaluasi

$\boldsymbol{F W}$ : Nilai bobot faktor

$\boldsymbol{E} \quad$ : Nilai evaluasi faktor

3) Perhitungan nilai total evaluasi ditunjuk dalam persamaan (3).

$$
\sum_{i=1}^{n} W E_{i}=W E_{1}+W E_{2}+W E_{n}
$$

Keterangan :

$$
\begin{array}{ll}
\sum_{i=1}^{n} W E_{i} & \\
W E_{i} & \text { : Total nilai bobot evaluasi } \\
& \text { Nilai bobot evaluasi ke }-i
\end{array}
$$

\subsection{Tanaman Pangan}

Tanaman pangan sendiri terbagi 2 yaitu tanaman palawija dan juga tanaman utama yaitu padi. Tanaman palawija dapat dikatakan sebagai tanaman kedua setelah tanaman utama dari padi. Tanaman pangan adalah tanaman yang dimanfaatkan dan diolah untuk memenuhi kebutuhan akan makanan bagi manusia [1].

\section{Metodologi}

Metodologi penelitian dibuat agar berjalan sesuai dengan tujuan yang telah di tentukan sehingga mencapai hasil yang baik. Metodogi penelitian dapat dilihat pada Gambar 1 di bawah ini : 


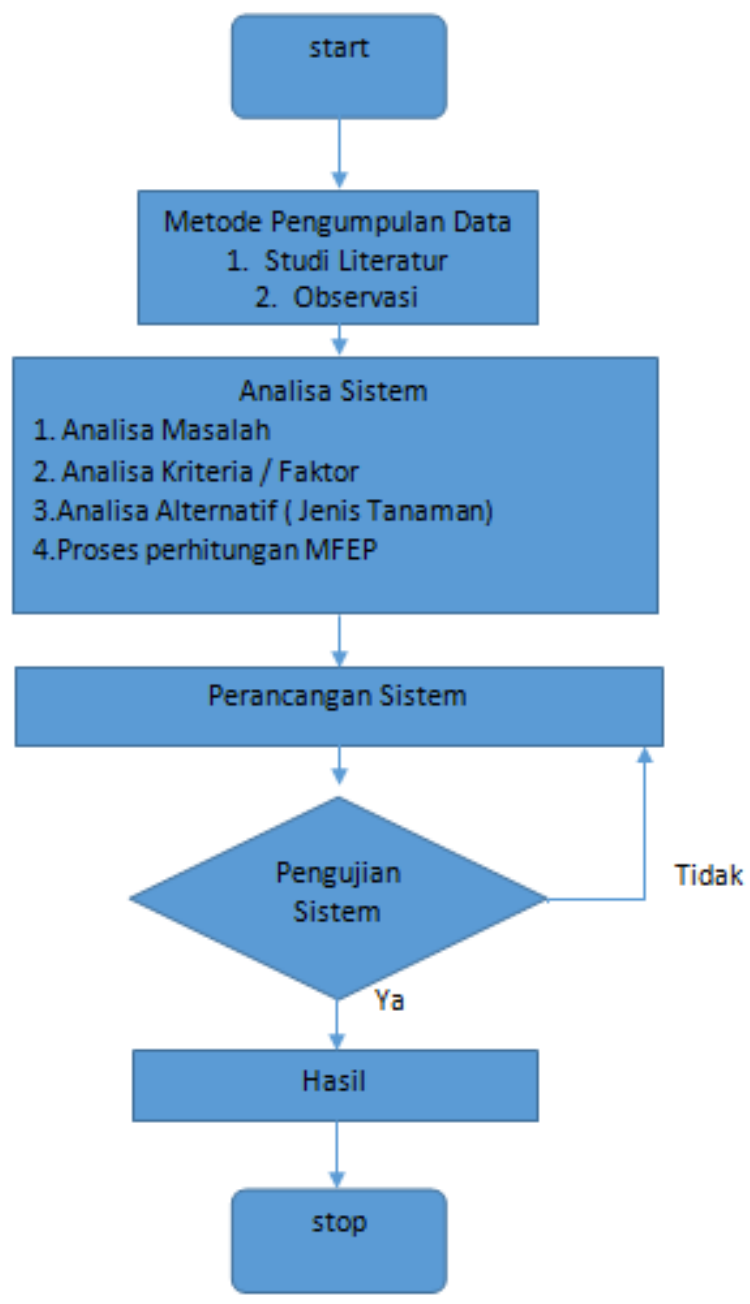

Gambar 1. Metodologi Penelitian

\section{Hasil dan Pembahasan}

\subsection{Analisa Sistem}

Berdasarkan data yang terkumpul dari observasi dilakukan analisa sistem, data berupa beberapa alternatif (jenis tanaman) dan kriteria / faktor. Langkah selanjutnya mengalisa data kriteria dan alteratif, yang nantinya digunakan untuk melakukan proses perhitungan menggunakan metode multi factor evaluation process. Sehingga nanti mendapatkan hasil berupa perangkingan yang bisa dijadikan sebagai dasar dalam pengambilan keputusan. Proses MFEP dapat dilihat pada flowchart pada Gambar 2 [9]. 


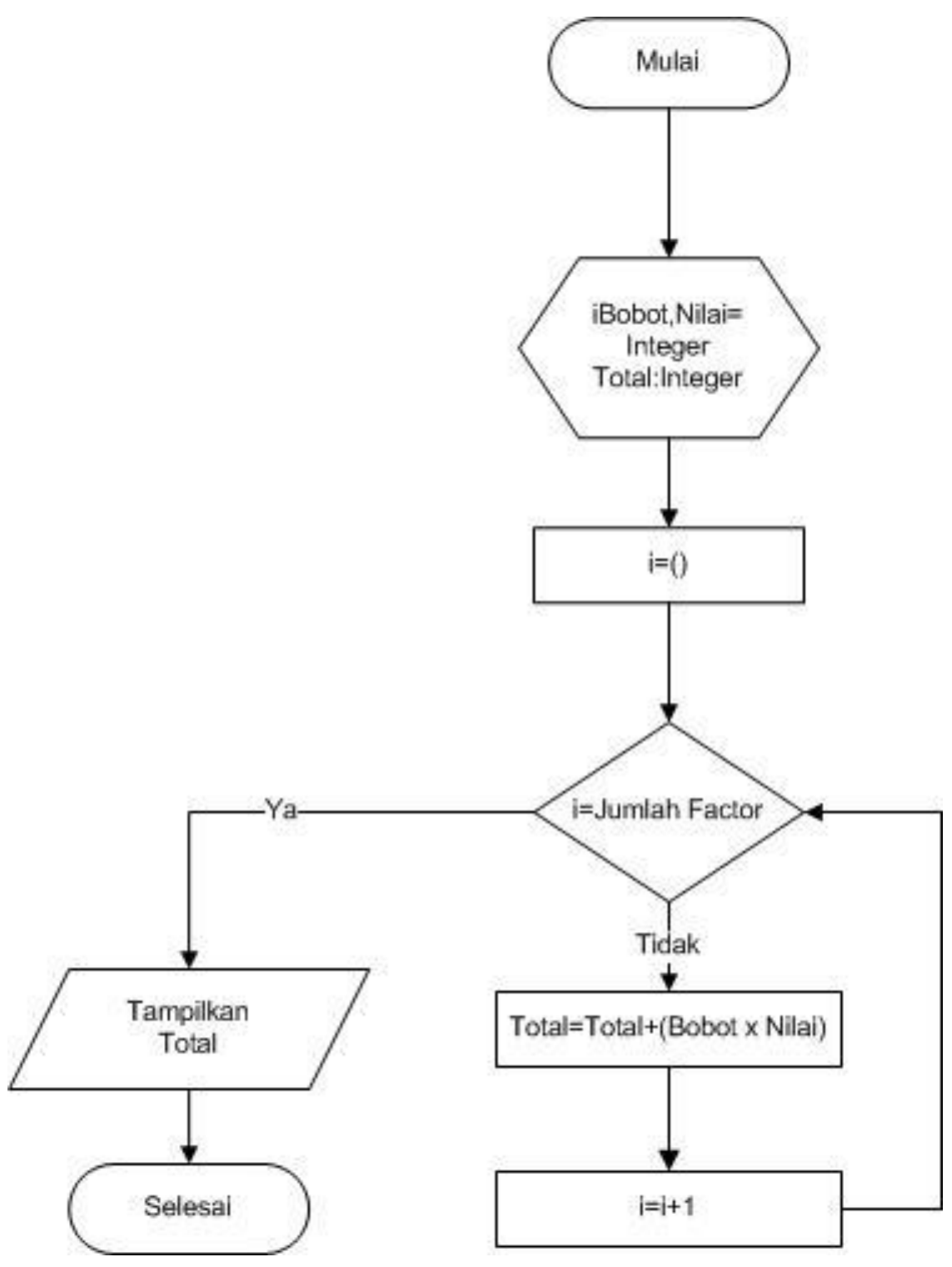

Gambar 2. Flowchart MFEP

\subsection{Analisis Kriteria dan Alternatif}

Data kriteria yang didapatkan dalam observasi dapat dilihat pada Tabel 1 di bawah ini :

\begin{tabular}{lll}
\multicolumn{3}{c}{ Tabel 1. Data Kriteria pemilihaan jenis tanaman pangan } \\
\hline No & Inisial & Kriteria \\
\hline 1 & A & Jenis Lahan \\
2 & B & Lingkungan \\
3 & C & Tadah hujan \\
4 & D & Pembibitan \\
\hline
\end{tabular}

Data Alternatif yang dididapatkan dalam observasi, dapat dilihat pada Tabel 2 di bawah ini : 
Tabel 2. Data Alternatif pemilihan jenis tanaman pangan

\begin{tabular}{ll}
\hline No & Alternatif \\
\hline 1 & Padi \\
2 & Jagung \\
3 & Singkong \\
4 & Sagu \\
5 & Kentang \\
\hline
\end{tabular}

Setelah data kriteria / faktor dan alternatif (tanaman) didapatkan langkah selajutnya melakukan perhitugan menggunakan metode MFEP.

\subsection{Perhitungan Menggunakan Metode MFEP}

Langkah-langkah pemecahan menggunakan metode MFEP adalah sebagai berikut :

1) Dalam menentukan nilai bobot, penulis mencoba memasukan nilai sebagai sample perhitungan dimana bobot faktor total pembobotan harus sama dengan $1\left(\sum\right.$ pembobotan $\left.=1\right)$ atau disebut factor weight. Dapat dilihat pada Tabel 3 di bawah ini:

\begin{tabular}{lll} 
& \multicolumn{2}{c}{ Tabel 3. Faktor dan Pembobotan } \\
\hline No & Faktor & Bobot \\
\hline 1 & Jenis Lahan & 0,3 \\
2 & Lingkungan & 0,2 \\
3 & Tadah Hujan & 0,1 \\
4 & Pembibitan & 0,4 \\
\hline & Total $\sum$ & 1 \\
\hline
\end{tabular}

2) Mengisikan Nilai bobot faktor sesuai dengan beberapa alternatif yang dijadikan sebagai kandiditat pemilihan tamanan. Nlai bobot faktor dan alternatif dapat dilihat pada Tabel 4 di bawah ini:

Tabel 4. Nilai Faktor dan alternatif

\begin{tabular}{lllll}
\multicolumn{5}{c}{ Tabel 4. Nilai Faktor dan alternatif } \\
\cline { 2 - 5 } Alternatif & A & B & C & D \\
\hline Padi & 7 & 8 & 8 & 7 \\
Jagung & 7 & 6 & 5 & 9 \\
Singkong & 8 & 5 & 7 & 6 \\
Sagu & 9 & 8 & 5 & 4 \\
Kentang & 6 & 7 & 9 & 4 \\
\hline
\end{tabular}

3) Proses perhitungan weight evaluation merupakan perhitungan antara factor weight dan factor evaluation dengan penjumlahan, dari hasil weight evaluation dapat menentukan hasil evaluasi. Berikut adalah perhitungan weight evaluation pada beberapa alternatif.

a) Weight Evaluaton Jenis Lahan

$$
\begin{aligned}
W E= & F W x E \\
\mathrm{~W}_{\text {padi }} & =7 * 0,3 \\
& =2,1 \\
\mathrm{~W}_{\text {jagung }} & =7 * 0,3 \\
& =2,1 \\
\mathrm{~W}_{\text {singkong }} & =8 * 0,3 \\
& =2,4 \\
\mathrm{~W}_{\text {sagu }} & =9 * 0,3 \\
& =2,7
\end{aligned}
$$




$$
\begin{aligned}
\mathrm{W}_{\text {kentang }} & =6 * 0,3 \\
& =1,8
\end{aligned}
$$

Dari hasil perhitungan tersebut diperoleh nilai weight evaluation. Nilai weight evaluation dapat dilihat pada Tabel 5 di bawah ini:

Tabel 5 Nilai Weight Evalauation

\begin{tabular}{lcccc}
\hline & \multicolumn{4}{c}{ Faktor } \\
\cline { 2 - 5 } Alternatif & $\mathrm{A}$ & $\mathrm{B}$ & $\mathrm{C}$ & $\mathrm{D}$ \\
\hline Padi & 2,1 & 1,6 & 0,8 & 2,8 \\
Jagung & 2,1 & 1,2 & 0,5 & 3,6 \\
Singkong & 2,4 & 1 & 0,7 & 2,4 \\
Sagu & 2,7 & 1,6 & 0,5 & 1,6 \\
Kentang & 1,8 & 1,4 & 0,9 & 1,6 \\
\hline
\end{tabular}

b) Menjumlahkan seluruh hasil weight evaluation untuk memperoleh total hasil evaluasi

$$
\begin{aligned}
\sum_{i=1}^{n} W E_{i}=W E_{1} & +W E_{2}+W E_{n} \\
\sum \mathrm{W}_{\text {padi }} & =2,1+1,6+0,8+2,8 \\
\sum \mathrm{W}_{\text {jagung }} & =7,3 \\
\sum \mathrm{W}_{\text {singkong }} & =2,1+1,2+0,5+3,6 \\
& =7,4 \\
\sum \mathrm{W}_{\text {sagu }} & =6,4+1+0,7+2,4 \\
\sum \mathrm{W}_{\text {kentang }} & =2,7+1,6+0,5+1,6 \\
& =6,4 \\
& =1,8+1,4+0,9+1,6 \\
& =5,7
\end{aligned}
$$

Total hasil evaluasi dapat dilihat pada Tabel 6 berikut.

\begin{tabular}{lccccc}
\multicolumn{7}{c}{ Tabel 6. Total Hasil Evaluasi } \\
\hline \multirow{2}{*}{ Alternatif } & $\mathrm{A}$ & $\mathrm{B}$ & $\mathrm{C}$ & $\mathrm{D}$ & $\sum \mathrm{W}$ \\
\cline { 2 - 6 } Padi & 2,1 & 1,6 & 0,8 & 2,8 & 7,3 \\
Jagung & 2,1 & 1,2 & 0,5 & 3,6 & 7,4 \\
Singkong & 2,4 & 1 & 0,7 & 2,4 & 6,5 \\
Sagu & 2,7 & 1,6 & 0,5 & 1,6 & 6,4 \\
Kentang & 1,8 & 1,4 & 0,9 & 1,6 & 5,7 \\
\hline
\end{tabular}

Berdasarkan Tabel 6 diatas, dapat dilihat bahwa tanaman yang menjadi pilihan adalah tanaman jagung dengan nilai 7,4.

\subsection{Perancangan Sistem}

Hasil peracangan sistem yang terdiri dari diagram konteks dan Data Flow Diagram (DFD) level 1 sebagaimana dijelaskan pada Gambar 3 dan Gambar 4. Pada Gambar 4 dan Gambar 5 dijelaskan bahwa sistem yang di rancang terdiri dari entitas admin dan kepala dinas tanaman pangan. Admin disini membantu kepala dinas untuk menginputkan jenis tanaman serta faktor-faktor yang mempengaruhi dalam pemilihan jenis tanaman sehingga pimpinan mendapatkan perangkingan dalam pemilihan jenis tanaman yang cocok untuk ditanam di Kabupaten Musi Rawas. 


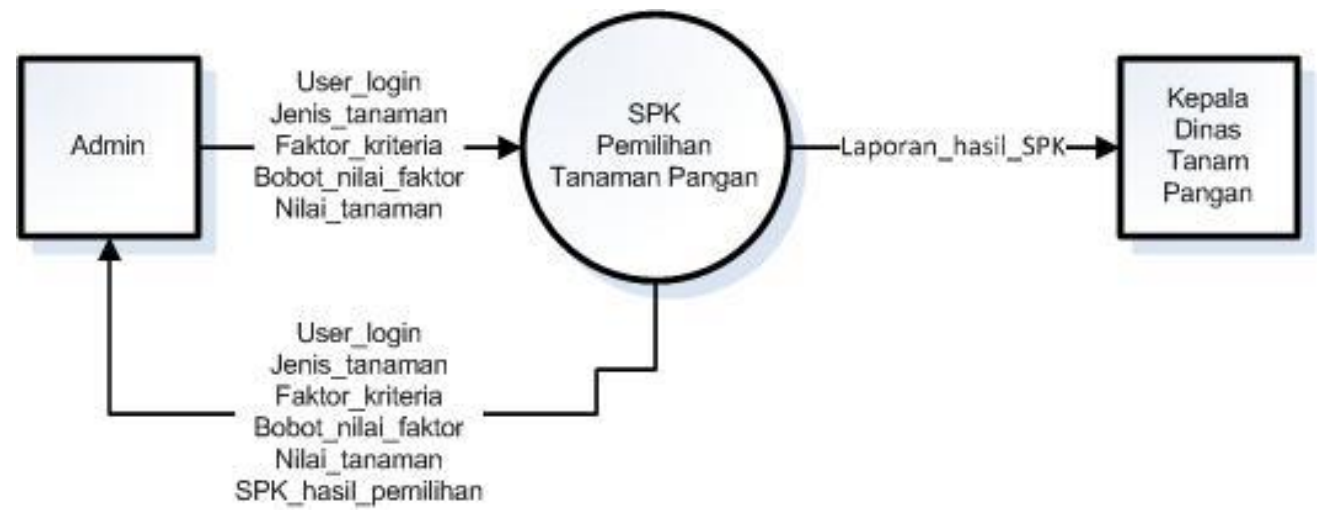

Gambar 3. Diagram Konteks

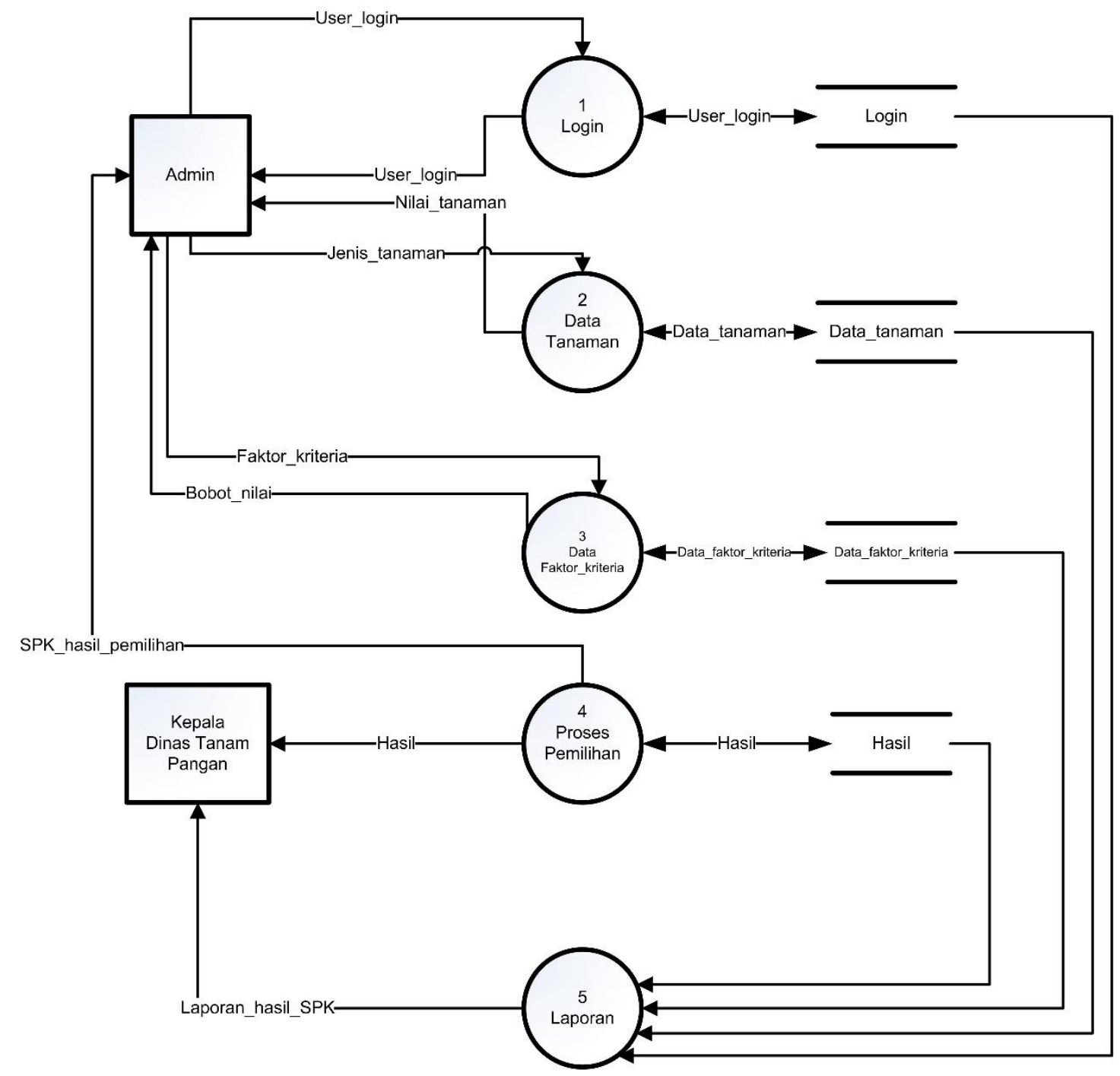

Gambar 4. DFD Level 1 


\subsection{Implementasi Sistem}

Dari analisa yang telah dilakukan maka selanjutnya sistem dirancang dan dibangun dengan bahasa pemograman PHP. Hasil implementasi berupa input alternatif (jenis tanaman), faktor / kriteria dan proses metode multi factor evaluation process dapat dilihat pada Gambar 5. Form input alternatif menjelaskan beberapa alternatif yang dimasukan sebagai kandidat dalam pemilihan jenis tanaman yang akan dijadikan sebagai objek dalam pemilihan tanaman yang cocok ditanam di Kabupaten Musi Rawas.

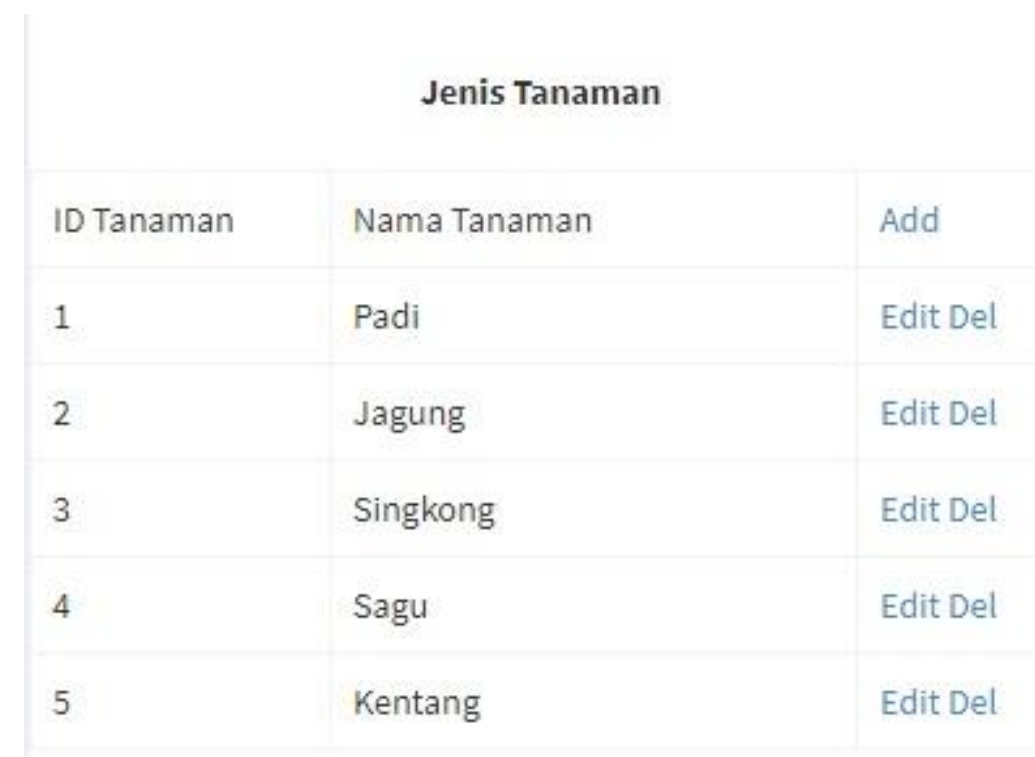

Gambar 5 Form Input Alternatif (Jenis Tanaman)

Form input faktor pada Gambar 6 menjelaskan beberapa faktor yang mempengaruhi dalam pemilihan jenis tanaman yang dapat dijadikan keputusan tanaman yang cocok ditanm di Kabupaten Musi Rawas.

\section{Data Faktor}

$\begin{array}{llll}\text { ID Faktor } & \text { Nama Faktor } & \text { Bobot Faktor } & \text { Add } \\ 1 & \text { Jenis Lahan } & 0,3 & \text { Edit Del } \\ 2 & \text { Lingkungan } & 0,2 & \text { Edit Del } \\ 3 & \text { Tadah Hujan } & 0,1 & \text { Edit Del } \\ 4 & \text { Pembibitan } & 0,4 & \text { Edit Del }\end{array}$

Gambar 6 Form Input Faktor / Kriteria

Hasil MFEP merupakan hasil perhitungan dari beberapa alternatif dan faktor sehingga mendapatkan perangkingan yang menjadi bahan pertimbangan pimpinan untuk menentukan keputusan dalam pemilihan tanaman yang cocok di tanam di Kabupaten Musi Rawas. Hasil perhitungan tersebut adalah sebagaimana yang ditampilkan pada Gambar 7. 


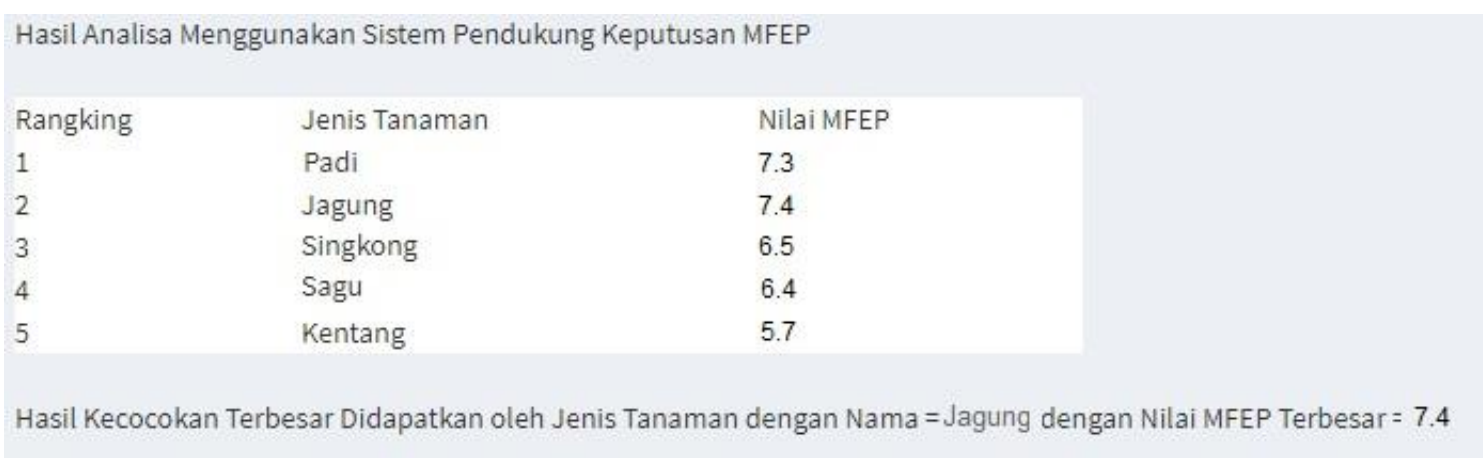

Gambar 7. Hasil MFEP

\section{Kesimpulan}

\subsection{Simpulan}

Berdasarkan perhitungan serta perancangan sistem yang telah dilakukan, maka penulis menarik kesimpulan bahwa pengambilan keputusan pemilihan tanaman pangan yang ada di Kabupaten Musi Rawas dapat dilakukan dengan menggunakan metode Multi Factor Evaluation Process. Beberapa hal yang perlu digaris bawahi antara lain:

1) Berdasarkan perhitungan SPK metode MFEP di dapatkan hasil bahwa jenis tanaman jagung merupakan alternatif terbaik.

2) Pemberian bobot faktor kriteria dapat mempengaruhi penilaian dan hasil perhitungan metode MFEP.

\subsection{Saran}

Berdasarkan hasil penelitian yang telah dilakukan, berikut adalah beberapa saran untuk pengembangan lebih lanjut terhadap sistem pengambilan keputusan menggunakan metode MFEP :

1) Penelitian ini masih menggunakan 4 faktor berdasarkan observasi penulis dilapangan, faktor tersebut dapat dikembangkan menjadi lebih agar penelitian ini dapat menghasilkan penilaian yang efektif.

2) Memecahkan permasalahan ini, metode MFEP bukan metode satu-satunya yang dapat digunakan dapat pengambilan keputusan, alangkah lebih baik metode MFEP digabungkan dengan metode lain agar mendapatkan hasil yang efektif.

\section{Daftar Rujukan}

[1] RENSTRA Pembangunan Tanaman Pangan Holtikultura Kabupaten Musi Rawas.2015.

[2] Kusrini, 2007, Konsep dan Aplikasi Sistem Pendukung Keputusan. Yogyakarta : Andi Offset.

[3] Fazliani, dkk. "Sistem Pendukung Keputusan Pemilihan Jenis Bibit Unggul Kelapa Sawit Dengan Metode Analytic Hierarchy Process (AHP). Prosiding Seminar Ilmu Komputer dan Teknologi Infomasi,2017, e-ISSN 2540 - 7902 dan p-ISSN 2541-366X

[4] Dyna Marisa Khairina, dkk. "Penerapan Metode Technique for Others Preference by Similary to Ideal Solution (TOPSIS) Untuk Rekomendasi Pemilihan TV Layar Data.TEKNOSI Vol.02,No.01 : Universitas Mulawarman. 2016.

[5] Subhan,dkk. "Sistem Pendukung Keputusan Penilaian Kinerja Karyawan Menggunakan Metode Multi Factor Evaluation Process Pada PT. Konsuil Wilayah Sulawesi Tenggara.semanTIK Vol.2, No.1 : Universitas Halu Oleo, 2016.

[6] Muhamad Reza Oktaviana, Rani Susanto."Sistem Pendukung Keputusan Rekomendasi Pemilihan Program Studi Menggunakan Metode Multi Factor Evaluation Process di SMA Negeri 1 Bandung.Komputa Vol 3.No.2 : 2016.

[7] T.Henny Febriana Harumy,Indri Sulistianingsih.”Sistem Penunjang Keputusan Penentuan Jabatan Manager Menggunakan Metode MFEP Pada CV.SAPO DURIN.Semintar Nasional Teknologi Informasi dan Multimedia,2016,ISSN 2302-3805.STMIK AMIKOM.Yogyakarta 
[8] Iis Afrianty,Ravi Umbara."Sistem Pendukung Keputusan (SPK) Menentukan Kelayakan Calon Penerima Zakat Menerapkan Multi Factor Evaluation Process.Seminar Nasional Teknologi Informasi, Komunikasi dan Industri (SNTIKI).2016, ISSN 20859902.Pekanbaru

[9] Heni Pratiwi.”Sistem Pendukung Keputusan Penentuan Karyawan Berprestasi Menggunakan Metode Multifactor Evaluation Process.Jurnal Nasional.2014.Volume 5,Nomor 2. Halaman 95-101.Samarinda

[10] Hetty Rohayani."Analisis Sistem Pendukung Keputusan Dalam Memilih Program Studi Menggunakan Metode Logika Fuzzy.Jurnal Nasional Indonesia.2013.Volume 5,Nomor 1.Halaman 530-539.ISSN 2355-4614.Jambi 
Yogi Primadasa et al. / Jurnal Sisfo Vol. 07 No. 01 (2017) 47-58

\section{Halaman ini sengaja dikosongkan}

